\title{
Preparation of Water Soluble Polythiophenes Mediated by Highly Active Zinc
}

\author{
Seung-Hoi Kim and Jong-Gỵu Kim \\ Deparment of Chemistry, Dankook Chwersin, Cheonan 330-714. Korea. "E-mail: jkim 16iâdankook ack \\ ${ }^{\dagger}$ Rieke Metals, Inc. 1001 Kingbird Ra. Lincoln, NE 68521, USA \\ Received November 19, 2008. Accepted Alugust 17. 2009
}

\begin{abstract}
A convenient route for the preparation of water soluble polythiophenes is described. Reactions involving highly active zinc metal show unique properties, viz. tolerance of the ester group and regioselectivity to the thiophene ring. Poly [3-(ethyl-f-alkanoate)thiophene-2,5-div1]s, poly [3-(n-carboxyalkyl)thiophene-2,5-diyi] s, and poly [3-(potassium- 7 -alkanoate)thiophene-2,5-diy:l]s were easily prepared by utilizing highly active zinc.
\end{abstract}

Key Words: Water soluble, Polythiophenes, Active zinc, Polymerization

\section{Introduction}

In 1980. a very interesting material, polythiophene. was introduced into the field of polymer chemistry. ${ }^{1}$ However, its application has remained severely limited due to its insolubility in normal organic solvents. Much efforts has been made performed to circumvent this difficulty. A major breakthrough was made by introducing an alkyl group on the 3-position of the thiophene ring. known as poly 3-alkylthiophene (P3AT). ${ }^{2}$ This class of poly mers has very unique properties: good solubility. processibility, and more interestingly high electroactivity. On the other hand. the introduction of an alkyl group onto the thiophene ring also resulted in other difficulties. As shown in Scheme 1, four different polymer linkages in the polymer chain could be obtained: HT-HT. HT-HH. TT-HT. and TT-HH.

It has been clearly demonstrated that the HT regioregular polymers have the improved electroconductivities. optical nonlinearity, and magnetic properties compared to the regiorandom polymers. Therefore more studies have focused on the preparation of regioregular poly thiophenes. This has been accomplished mostly by utilizing $\mathrm{Zn}^{*}{ }^{*}$ the Grignard route. and the Suzuki method."

A few months after since the discovery of organic-solventsoluble poly 3-alkylthiophenes. water soluble polythiophenes were introduced by Heeger. ${ }^{7}$ Little work. however, has been done on these water soluble polythiophenes. These polymers

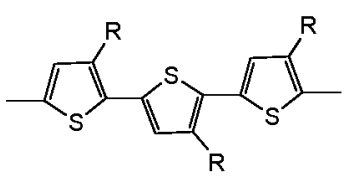

HT-HT

HT-HH

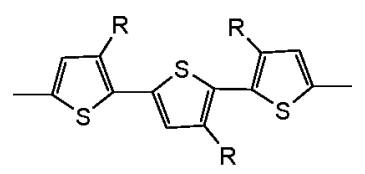

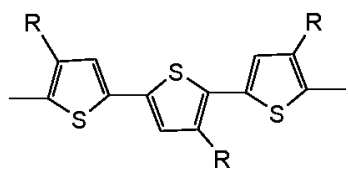

TT-HT

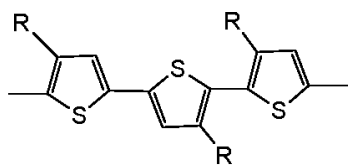

TT-HH have been prepared by introducing a polar functional group. such as alkanoic acid. ${ }^{8}$ phosphonic acid. ${ }^{9}$ sulfonate. ${ }^{8}$ and oxy-sulfonate. ${ }^{1, j}$ onto the thiophene ring.

Herein, we present a new approach to the preparation of water soluble polythiophenes. mediated by highly active zinc metal $\left(\mathrm{Zn}^{*}\right)$.

\section{Results and Discussion}

Preparation of $n$-ethoxy-n-0xoalkylzinc bromides(1a-1d). been recognized as an outstanding reagent that has a significant tolerance for some functional groups. Compared to organolithium and Grignard reagents, organozinc reagents have less reactivity toward electrophiles. Due to this big advantage. it has been widely used in organic synthesis. In this research. the unique reactivity of highly active zinc played a very important role in the preparation of the monomer as well as poly mer. Scheme 2 shows a general schematic diagram for the preparation of the organozinc reagents.

Ethyl haloalkanoates were added to the active zinc solution at $\mathrm{rt}$. The Oxidative addition of active zinc was easily completed within a few hours. After allowing the solution to settled down for a few hours at it., the supernatant was cannulated into the flask containing 3-bromothiophene in THF in the presence of $\mathrm{Ni}$ (dppe) $\mathrm{Cl}_{2}$ catalyst. The coupling reaction could be performed at $\mathrm{rt}$. and/or refluxing temperature. The final Among the many organometallic reagents. organozinc has

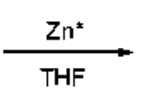

Scheme 2. Preparation of organozinc reagents.

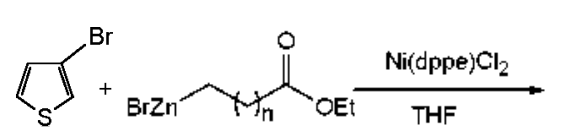<smiles>CCOC(=O)NCc1ccsc1</smiles>

1a-1d

Scheme 1. Four regioisomers.

Scheme 3. Preparation of Ethyl $n$-(3-thienyl)alkanoates. 
product was easily purified by either distillation or columu chromatrography using silica gel and heptane as the eluent. Higher yields were obtained from longer chain length substrates.

Bromination of ethyl 3-thienylalkunoates(2a-2d). Two wellknown brominating agents were able to be used for the bromination of thiophene derivatives. Both of bromine and NBS in methy lene chloride gave a very successfully results. All of the reactions were performed at rt within an hour, and then distillated off after a nomal work-up procedure. Generally. more than $90 \%$ isolated yields were obtained and the products were pure enough $(>98 \%$ ) for the polymerization.

Polymerization; regio-controlled synthesis of poly [3-(ethy]n-alkanoate)thiophene-2,5-diyl](3a-3d). In 1992, Rieke and co-workers reported that the active zinc underwent direct oxidative addition to 3-alkyl-2.5-dibromothiophene chemoselectively to afford 2-(bromozincio)-5-bromothophene quantitatively. We further examined the reactivity of highly active zinc toward dibrominated thiophene derivatives containing a functional group such as an ester group. Interestingly. both regioselectivity and tolerance toward various functionalities were observed in this reaction.

The oxidative addition of $\mathrm{Zn} \mathrm{n}^{*}$ was easily carried out at $0{ }^{\circ} \mathrm{C}$. and occurred predominantly at the 5-position of the dibrominated thiophene predominantly. The results are summarized in Table 1.

Again. $\mathrm{Zn}$ * has shown a good tolerance for ester group on

Table 1. Regioselectivity of active zinc<smiles>CCOC(=O)Cc1cc(Br)sc1Br</smiles>

I<smiles>CCOC(=O)CCc1cc(Br)sc1[14CH2]Br</smiles>

II

\begin{tabular}{lll}
\hline & $\underline{\mathbf{I}}$ & $\underline{\text { II }}$ \\
\hline $\mathrm{n}=2$ & 80 & 20 \\
$\mathrm{n}=3$ & 80 & 20 \\
$\mathrm{n}=4$ & 83 & 17 \\
$\mathrm{n}=5$ & 84 & 16 \\
\hline
\end{tabular}<smiles>CCOC(=O)NCc1ccsc1</smiles>

1a-1d

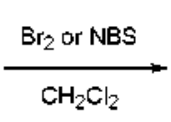

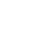<smiles>CCOC(=O)NCc1cc(Br)sc1Br</smiles>

2a-2d thiophene ring during the oxidative addition. Since a variety of different alkyl chain lengths are commercially available. a number of different polymers could be prepared by this methodology. It is also of interest that the ester group on the polymers can be easily converted to other functionalities.

The Polymerization of the organozinc reagents obtained above was carried out at rt. As described in previous studies. ${ }^{4}$ $\mathrm{Ni}$ (dppe)Cl2 was the best catalyst for the polymerization of the thiophene derivatives in term of the regiochemistry of the polymer. In this study. $\mathrm{Ni}(\mathrm{dppe}) \mathrm{Cl}_{2}$ was also successfully applied to the polymerization of the organozinc reagents. To complete the polymerization. the reaction mixture was stirred at rt. for 24 to $48 \mathrm{~h}$. Quencluing and washing with methanol gave a dark black polymer. For the analy sis of molecular and regiochemistry. the polymer was further purified by Soxhlet extraction with hexanes.

Previous reports showed that the $\alpha$-methylene protons of the alkyl group could be resolved differently. Based upon the ${ }^{1} \mathrm{H}$ NMR study, the resulting polymers were obtained in $50 \sim$ $80 \%$ yields with more than $90 \%$ regioregularity. The molecular weight was detemuined by gel permeation cluromatography (THF as eluent. poly'styrene standards for calibration): $\mathrm{Mw}=$ 20000. PDI $=1.32$

Pieparations of poly[3-(n-carboxyalkyl)thiophene-2,5-diyl]s, $(\downarrow \mathrm{a}-\downarrow d \mathrm{~d})$, and poly [3-(potassium- $n$-allkanoate)thiophene-2,5diyl]s, (5a-5d). Due to the wide range of applications of poly 3-alklylthiophenes. many studies have focused on the usage of water soluble poly thiophenes. ${ }^{\text {l }}$ Of these, poly(thiophene-3alkanoic acid)s have been generally been used. However. a very limited number of studies have been reported on the preparation of poly (thiophene-3-alkanoic acid). ${ }^{8.12}$ One of these studies was performed by the Stille/CuO polymerization of an oxazoline protected monomer followed by acidic hydroly sis. ${ }^{12}$ Herein, we would like to report a new route for the preparations of poly (thiophene-3-alkanoic acid). and poly [3-(potassium-n-alkanoate)thiophene-2.5-diyl]. which were accomplished by utilizing 3a-3d shown above. Schematic diagrams are shown in Scheme 6.

These water soluble polymers were obtained by the basic
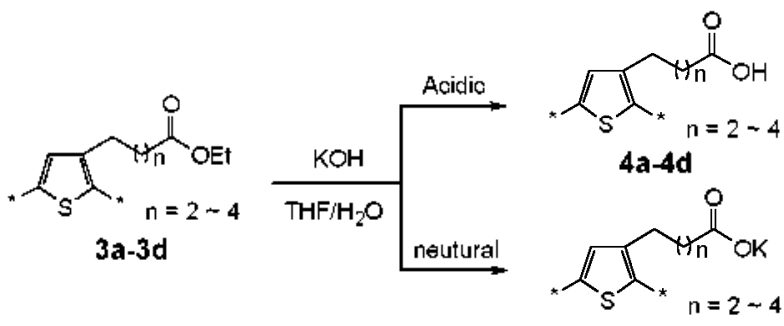

5a-5d

Scheme 4. Bromination of Ethyl n-(3-thienyl balkanoates.

Scheme 6. Hydrolysis<smiles>CCOC(=O)CCc1cc(Br)sc1Br</smiles>

2a-2d<smiles>CCOC(=O)CCc1cc(Br)sc1Br</smiles>

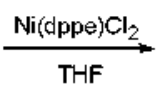<smiles>CCOC(=O)CCc1cc(C)sc1C</smiles>

Scheme 5. Polymerization. 
hydrolysis of the polymers 3a-3d. A mixture of the THF solution of the polymers 3a-3d and aqueous $\mathrm{KOH}$ solution was stirred at refluxing temperature overnight. Two different types of polymers were formed depending upon the work-up procedure. As described in Scheme 6. an acidic quenching after hydroly sis gave poly(thiophene-3-alkanoic acid), ta-4d. In order to remove any left over 3a-3d. the resulting polymer was purified by Soxhlet extraction with chloroform. It was observed that the resulting acidic polymers ta-td were not soluble in any organic solvents. but very soluble in a basic aqueous media. Even though the no NMR study of these polymers was performed. it was concluded that the same regioregularity as the precursor might be maintained.

The use of a slightly different work-up procedure resulted in another types of poly mers. corresponding potassium salts. 5a-5d After being hydrolyzed. the whole mixture was poured into THF affording a very sticky oily product. The oily product was solidified from the mixture of THF and methanol. Soxhlet extraction of the resulting poly mer with chloroform gave the water-soluble polymer as a black solid. This procedure could be utilized for the preparation of a variety of different types of polymers containing different salts.

\section{Conclusions}

For the first time. we have developed a new practical method for the preparation of high regioregular poly [3-(ethyl-nalkanoate)thiophene-2,5-diyl] (3a-3d). It has been accomplished by utilizing a highly active zinc and thiophene derivatives containing a functional group such as an ester group. Interestingly a simple treatment of the resulting polymers (3a-3d) afforded a variety of different types of water-soluble polymers (4a-4d, and 5a-5d).

\section{Experimental Section}

A representative procedure for each step is described below.

Preparation of ethyl 3-thienylhexanoate (1d). $\mathrm{LiBr}$ (17.4 g. $200 \mathrm{mmol}$ ) was placed in a $1.0 \mathrm{~L}$ RBF and then $200 \mathrm{~mL}$ of THF was added at $\mathrm{rt} .3$-Bromothiophene $(24.4 \mathrm{~g} .150 \mathrm{mmol})$ was then added into the flask. While being stirring the mixture. 6-ethoxy-6-oxohexylzinc bromide solution $(0.5 \mathrm{M}$ in THF, $400 \mathrm{~mL}, 200 \mathrm{mmol}$ ), prepared by using highly active Zinc, "was cannulated into the mixture over a period of $1.0 \mathrm{~h}$. The resulting mixture was allowed to stirred at rt. overnight. After quenching with $3 \mathrm{M} \mathrm{HCl}$ solution, the mixture was extracted with ether. Standard work-up and then vacuum distillation afforded $24 \mathrm{~g}$ of $1 \mathrm{~d}(71 \%$, isolated yield).

Bromination; preparation of ethyl 3-(2,5-dibromothienyl) hexanoate (2d). In a $1.0 \mathrm{~L}$ RBF equipped with an addition funnel, ethyl 3-thienylhexanoate. 1d, (4+ g. $180 \mathrm{mmol})$ was placed. and then $400 \mathrm{~mL}$ of $\mathrm{CH}_{2} \mathrm{Cl}_{2}$ was also added. Into the addition funnel, bromine $(58.6 \mathrm{~g} .360 \mathrm{mmol})$ and $40 \mathrm{~mL}$ of $\mathrm{CH}_{2} \mathrm{Cl}_{2}$ were added. Next. bromine solution was added slowly added to the reaction mixture while being stirred at it. Bromination was completed in $10 \mathrm{~min}$ after the addition was finished. The resulting mixture was quenched with saturated
$\mathrm{Na}_{2} \mathrm{~S}_{2} \mathrm{O}_{3}$ solution and then the organic phase was washed with saturated $\mathrm{NaHCO}_{3}$ solution and brine. The crude product was distillated under high vacuum pressure to afford $66 \mathrm{~g}$ of ethyl 3 -(2,5-dibromothienyl)hexanoate as a light yellow oil $(93 \%$ isolated yield).

Polymerization; preparation of poly [3-(ethylhexanoate) thiophene-2,5-diyl](3d). Highly active zinc ( $12 \mathrm{~g} .180 \mathrm{mmol}$ ) was added into a $250 \mathrm{~mL} \mathrm{RBF}$, and then the flask was cooled down in an ice-bath. With being stirred at $0^{\circ} \mathrm{C}$, etlyy $3-(2.5-$ dibromothienyl)hexanoate. 3d. (66 g. $165 \mathrm{mmol}$ ) was cannulated into the flask. The resulting nuxture was allowed to stirred at $0^{\circ} \mathrm{C}$. The oxidative addition was completed in $1 \mathrm{~h}$. The mixture was allowed to settle down and then the supernatant organozinc solution was used for the polymerization.

In a $250 \mathrm{~mL}$ RBF. $\mathrm{Ni}$ (dppe) $\mathrm{Cl}_{2}(0.31 \mathrm{~g} .0 .58 \mathrm{mmol})$ was placed and then $5.0 \mathrm{~mL}$ of THF was added. Next, the organozinc solution prepared above was cannulated into the catalyst solution while being stirning it. After being stirred at it for $48 \mathrm{~h}$, the resulting mixture was poured into $500 \mathrm{~mL}$ of methanol to afford a black precipitation. The polymer was then filtered and washed with methanol. Soxllet extraction with hexanes afforded $33 \mathrm{~g}$ of a black polymer.

Preparation of poly(thiophene-3-hexanoic acid)( 4 d). $22 \mathrm{~g}$ (100 mmol. based on monomer unit) of polymer was added into a $250 \mathrm{~mL}$ RBF. then $200 \mathrm{~mL}$ of THF was added to dissolve the polymer. Into the resulting deep brown solution was added $\mathrm{KOH}(6.2 \mathrm{~g} .110 \mathrm{mmol})$ solution dissolved in $200 \mathrm{~mL}$ of $\mathrm{H}_{2} \mathrm{O}$. The resulting mixture was heated to reflux while being stirred and then cooled down to it after being refluxed for overnight. Next, $3 \mathrm{M} \mathrm{HCl}$ solution was added into the resulting mixture. A black precipitation was obtained. The polymer was then filtered and washed with $\mathrm{H}_{2} \mathrm{O}$. then dried under high vacuum pressure. The resulting polymer was Soxllated with chloroform over $24 \mathrm{~h}$. then dried to give $17 \mathrm{~g}(90 \%$. yield) of a dark black polymer.

Preparation of poly [3-(potassium-6-hexanoate)thiophene2,5-diỵl] (5d). The hydrolysis of 3d was carried out as described above. After the hydrolysis was completed. the resulting misture was poured into THF. An oily product was obtained on the bottom of the flask. The solvent was decanted off and then the residue oily product was poured into a mixture of methanol and THF. The resulting solidified polymer was filtered and washed with methanol and then dried under high vacuum pressure affording a black powder-like polymer. An isolated yield $85 \%$ was obtained.

Aclonowledgments. The present research was conducted by the research fund of Dankook University in 2009.

\section{Refelences}

1. (a) Yamamoto, K.; Sanechika, A.; Yamamo, A. J. Polm. Sci., Potym. Lett. Ed. 1980 , 18, 9. (b) Lin, T. W. P.; Dudek, L. P. J. Polum. Sci., Polm Chem. Ed. 1980, 18, 2869.

2. (a) Jen, K. Y.: Oboodi, R.; Elsenbalumer, R. L. Polym Mater Sci. Eng. 1985, 53, 79. (b) Elsenbalumer, R. L.: Jen, K. Y.; Oboodi, R. Sinth. Het $1986,15,169$

3. (a) Reitzel, N.; Greve, D. R.; Kjar, K.; Howes, P. B.; Jayaraman, M.; Savoy, S. M.; McCullough, R. D.; McDevitt, T. T.; Bjonholm, 
T. B. J. Am. Chem. Soc. 2000, 122, 5788.

4. Chen, T.-A.: Rieke, R. D. J. Am. Chem. Soc, 1992, 1H, 10087.

5. MeCullough. R. D.: Lowe. R. D. J. Chem. Soc. Chem. Commun. 1992,70 .

6. Liversedge, I. A.; Higgins, S. J; Giles, M.: Heeney, M. McCullough, I. Tetrahedron Lett. 2006, $47,5143$.

7. Patil, A. O.; Ikenoue, F.; Wudl, F.: Heeger, A. J. $J$. Am. Chem. Soc. $1987,109,1858$

8. (a) McCullough, R. D.; Ewbank, P. C.; Loewe, R. S. J. An. Chem. Soc. 1997, 119, 633. (b) Kim, B.: Chen, L.; Gong, J.;
Osada, Y. Macromolecules 1999, 32, 3964. (c) Chaver, M.; Faid, K.; Leclerc, M. Chem. Mater: 1997, 9, 2902.

9. Stokes, K. K.: Heuze, K.; McCullough, R. D. Macromolecules $2003,36,7114$.

10. Chayer, M.; Faid, K.; Leclerc, M. Chem. Mater. 1997, 9, 2902.

11. For more applications, See: 12(b), references cited therein.

12. (a) Zhai, L.; McCullough, R. D. Adw. Mater: 2002, Ht, 901, (b) Ewbark, P. C.; Loewe, R. C.; Zhai, L; Redding, J.; Sauve, G.; McCullough, R. D. Tetrahedron 2004, 60, 11269. 